\title{
COMPARISON OF TESTICULAR PROTEIN LABELLING IN CRYPTORCHIDISM INDUCED IN PREPUBERTAL AND ADULT RATS
}

\author{
JOSEPH R. DAVIS, ROBERT N. MORRIS \\ AND MANNFRED A. HOLLINGER \\ Department of Pharmacology and Therapeutics, \\ Stritch School of Medicine, and Graduate School, \\ Loyola University, Chicago, Illinois, U.S.A.
}

(Received 1st March 1965)

\begin{abstract}
Summary. Unilateral cryptorchidism has been produced in prepubertal rats by abdominal fixation of an undescended testis and in adult rats by transplantation of a previously descended testis from the scrotal sac into the abdominal cavity. The incorporation of L-lysine-U- ${ }^{14} \mathrm{C}$ into protein of slices of both types of experimentally induced cryptorchid testes 30 days following the surgical procedure has been found to be markedly greater than that observed for slices of contralateral, scrotal testes of the same animal.
\end{abstract}

It has long been known that cryptorchidism leads to severe spermatogenic damage. In addition, the undescended testis has been reported to be over thirty times more likely to become malignant as compared to a normal, scrotal testis (Campbell, 1942). For these reasons, our laboratory has initiated studies on the metabolism of mammalian testicular tissue beginning with an investigation of the incorporation of ${ }^{14} \mathrm{C}$-labelled lysine into rat testicular protein. It was initially found that the incorporation of $\mathrm{L}-\mathrm{lysine}-\mathrm{U}-{ }^{14} \mathrm{G}$ into protein of slices of cryptorchid testes which were experimentally-induced in adult rats was much greater than that observed for slices of scrotal testes obtained from the same animal (Davis, Morris \& Hollinger, 1964). The present experiments were designed to explore further this finding, as well as to investigate the physiological significance of inducing cryptorchidism by transplanting a previously descended adult testis from the scrotal sac into the abdominal cavity.

Unilateral cryptorchidism was experimentally produced in two groups of male Sprague-Dawley rats. The first group (five animals) consisted of prepubertal rats which were 20 days of age and in which the testes had not yet begun their descent. Abdominal fixation of the undescended testis was carried out by performing a midline abdominal incision under ether anaesthesia and suturing the right testis to the dorsolateral abdominal wall, thereby preventing its normal descent. A fine 6-O surgical silk suture was passed just under the 
tunica albuginea. Care was taken to avoid any interruption of the testicular artery by placing the suture beyond the point where the testicular artery enters the parenchyma of the testis. No evidence of testicular ischaemia was observed up to 30 days following the surgical treatment, which was the time period studied in the present investigations. Closure of the inguinal canal was not performed inasmuch as it was found that suturing alone was capable of preventing testicular descent. The left testis of the same animal was not sutured and was observed to descend into the scrotal sac when the animal reached approximately 35 days of age. Following abdominal fixation of the prepubertal testis, only a slight increase in weight was observed for the undescended, cryptorchid right testis, which reached a maximum weight of approximately

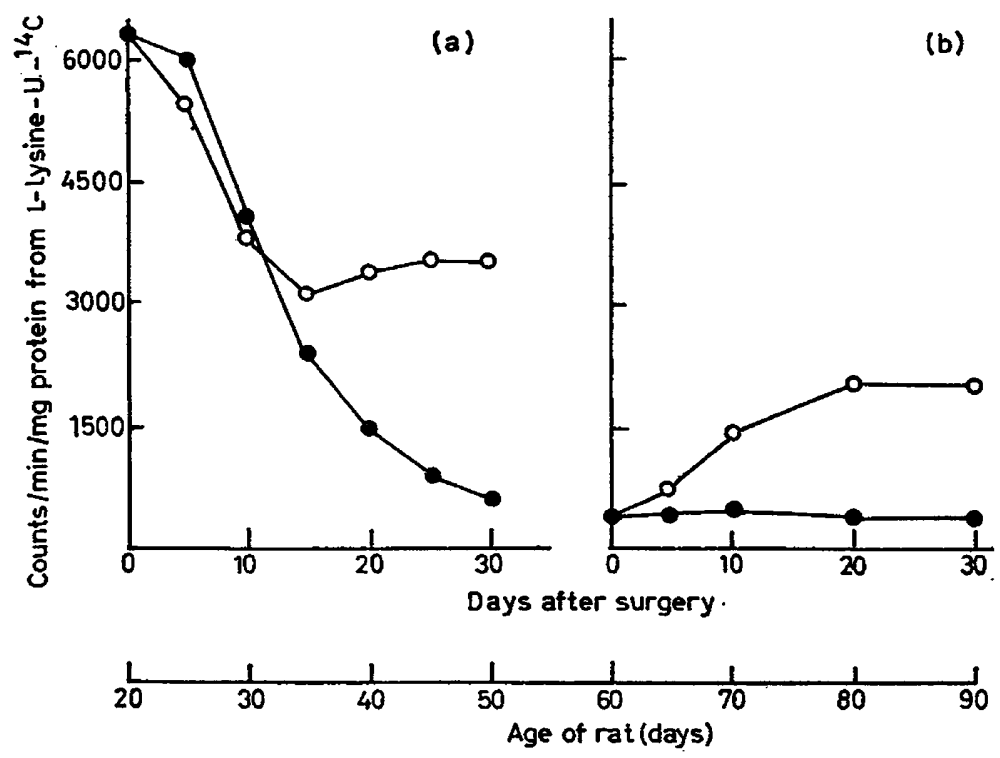

TEXT-PIG. 1. Incorporation of L-lysine-U-14 C into protein of slices of cryptorchid testes (O) following (a) abdominal fixation and (b) abdominal transplantation of testes in prepubertal and adult rats, respectively. - Scrotal testes. Each point on the graphs represents an average of five experiments.

300 to $400 \mathrm{mg}$ at the 20 th day after surgery. The left testis, on the other hand, showed a marked and continual increase in weight until the 30th day after the surgical procedure when it began to level off at approximately $1500 \mathrm{mg}$.

The second group (five animals) consisted of adult rats which were 60 days of age and whose testes had undergone a normal descent into the scrotal sac. Transplantation of the adult testis from the scrotal sac into the abdominal cavity was performed by making a midline abdominal incision and applying gentle pressure to the bottom of the scrotal sac. The right testis was then sutured to the dorsolateral abdominal wall in a similar manner to that previously described. The left testis of the same animal was allowed to remain in the scrotal sac to serve as a control. Following abdominal transplantation of the previously descended adult testis, a progressive decrease in the weight of the 
cryptorchid right testis occurred from approximately $1500 \mathrm{mg}$ to a weight of 300 to $400 \mathrm{mg}$ at the 20 th day post-operatively. The left scrotal testis of the same animal did not change in weight to any significant extent during this period. These data indicate that the difference in weight of the scrotal and the cryptorchid testis appears to be quite similar in both types of experimentallyinduced cryptorchidism.

At various time periods ranging from 5 to 30 days after the surgical procedure, the animals of both groups were killed and both scrotal and abdominal testes removed. Following excision of the capsule, slices of testes were obtained at $4^{\circ} \mathrm{C}$ with the aid of a Stadie-Riggs microtome. Incubation of the tissue slices was carried out in a Warburg apparatus as previously described (Davis, Firlit \& Hollinger, 1963). The main chamber of the flask contained 150 to $200 \mathrm{mg}$ wet weight of tissue in $3.0 \mathrm{ml}$ of Krebs-Ringer bicarbonate buffer at $\mathrm{pH} 7 \cdot 4$. The side-arm contained $2.5 \times 10^{5}$ counts $/$ min of L-lysine-U- ${ }^{14} \mathrm{C}$ in a volume of $0.2 \mathrm{ml}$. The final concentration of radioactive lysine in the incubation flask was $1.8 \times 10^{-5} \mathrm{M}$. The gas phase was $95 \% \mathrm{O}_{2}$ and $5 \% \mathrm{CO}_{2}$. At the end of a $1 \mathrm{hr}$ incubation period at $37.5^{\circ} \mathrm{C}$, the reaction was terminated by the addition of $0.3 \mathrm{ml}$ of $5 \mathrm{~N}$ perchloric acid. The proteins were isolated, plated and assayed for radioactivity, employing a correction for self-absorption.

Text-fig. 1 presents a comparison of the incorporation of $\mathrm{L}-\mathrm{lysine}-\mathrm{U}-{ }^{14} \mathrm{C}$ into protein of slices of cryptorchid rat testes which have been induced by both abdominal fixation of prepubertal testes and by abdominal transplantation of adult testes. The incorporation of labelled lysine into protein of the normal, scrotal testis was found to decrease markedly from a specific activity (counts/ $\mathrm{min} / \mathrm{mg}$ dry weight of protein) of over 6000 at 20 days of age to approximately 350 counts $/ \mathrm{min} / \mathrm{mg}$ at 60 days of age, where it remained constant throughout the remaining experimental period of the present studies. Protein labelling of the cryptorchid testis induced by the abdominal fixation of a prepubertal testis was also observed to decrease up to 15 days following its retention in the abdominal cavity; however, no further decrease in protein labelling occurred beyond this time so that, at 30 days after the surgical procedure, the specific activity of the protein of the cryptorchid testis was almost five times as great as the specific activity of the protein of the contralateral, scrotal testis. Following abdominal transplantation of a 60-day-old adult, scrotal testis, the uptake of $\mathrm{L}$-lysine-U- ${ }^{14} \mathrm{C}$ into protein of the cryptorchid testis was found to increase markedly, reaching a maximum at the 20th day after the surgical procedure while protein labelling of the contralateral, scrotal testis remained constant.

These data indicate that the marked increase in protein labelling from Llysine- $\mathrm{U}-{ }^{14} \mathrm{C}$ which has been observed in cryptorchid rat testes induced by transplanting an adult, scrotal testis into the abdominal cavity has been found to occur also in cryptorchid rat testes which have been induced by the more physiological condition of preventing normal testicular descent by fixation of the abdominal testis prior to the onset of puberty. The possibility exists that the increase in testicular protein labelling found to occur in cryptorchidism may be due to an increase rate of protein biosynthesis occurring in the remaining cell types of the abdominal testis. Experiments are now in progress in this laboratory which are designed to compare further both types of experimentally-induced 
cryptorchidism in terms of their histological appearance and radioautographic incorporation of tritiated lysine into protein of individual testicular cell types.

This investigation was supported by U.S. Public Health Service Research Grant HD 01573-01 from the National Institute of Child Health and Human Development.

\section{REFERENCES}

Camprell, H. E. (1942) Incidence of malignant growth of the undescended testicle; a critical and statistical study. Arch. Surg. 44, 353

Davis, J. R., FirLit, C. F. \& Hollinger, M. A. (1963) Effect of temperature on incorporation of Llysine-U.14G into testicular proteins. Amer. F. Physiol. 204, 696.

Davis, J. R., Morris, R. N. \& Hollinger, M. A. (1964) Incorporation of L-lysine-U-14C into proteins of cryptorchid testis slices. Amer. F. Physiol. 207, 50. 